\title{
INTEGRATING A SERVICE LEARNING PROJECT INTO AN ADVANCED WEB DEVELOPMENT COURSE
}

\author{
Gayle Jesse, Thiel College, Greenville, PA, giesse@thiel.edu
}

\begin{abstract}
Student success is a growing concern in higher education institutions. How can educators create courses that better prepare students for their future careers? The purpose of this paper is to present recommendations that will assist educators in helping students to be successful in college. This paper begins by briefly discussing a service-learning project (SLP). Next, the paper compares the advantages and disadvantages of completing a simulated project against a service-learning project in a web development course from a teacher's perspective. Additionally, this paper explores the students' and clients' perceptions of the advantages and disadvantages of SLPs. This paper also outlines a model for teaching a web development course with the integration of a service-learning project. Finally, the paper concludes with the idea that community service-based projects can benefit all parties involved and should be considered when designing the pedagogy for an advanced web development course. This study, along with others referenced in the paper, finds that service-learning projects provide a framework for structuring an effective course curriculum.
\end{abstract}

Keywords: Web design, Service Learning Project-based Web course, Advanced Web Site Design, Teaching a Web Development Course, Information Systems Education, Service Learning Projects, Community Service in Course Work

\section{INTRODUCTION}

The goal of most individuals is to become economically self-sufficient. Achieving this goal in an informationdriven world economy requires individuals to obtain an education beyond high school and a bachelor's degree is often preferred. How do postsecondary schools help students achieve success in college and ultimately success in life? Obviously, this is a difficult task for schools and it is increasingly important among federal agencies.

According to Jacoby (1996), service learning is an educational strategy that integrates service experiences with the academic curriculum and provides students with the opportunity for reflections. Furco (2002) states that service learning differs from a service-based internship in that the service-learning activities completed during the servicelearning project are to be cohesively integrated with the curricular content of academic course pedagogy. The completion of a service learning project provides students with the opportunity to apply the theoretical knowledge gained in a course with problem solving skills to complete a curriculum related project that meets a need in the community. Eyler and Giles (1999) contend that the primary motivation for integrating service learning into the higher education curriculum is to enhance student learning through the provision of community service. Moreover, service-learning projects are becoming a phenomenon; national movements are taking place in schools to incorporate active and collaborative learning activities into the curriculum.

\section{Research Questions}

RQ1: What perceptions do teachers have about service-learning projects versus simulated projects?

RQ2: What perceptions do college students have about service learning projects?

RQ3: What perceptions do clients/community organizations have about service learning projects?

Could service learning be the answer to students' achievement of success in school and life? If so, how do teachers and schools get started? This paper further presents several service-learning facts gathered by active researchers in the field of study. Moreover, this study gathered research to clarify what higher education learning institutions feel are the advantages and disadvantages of completing service-learning projects, as well as students and clients/community organizations. 
Volume XII, No. 2, pp. 22-29, 2011

\section{METHODOLOGY}

This research study explored how teachers, college students, and clients perceive service learning projects (SLPs) in higher education. The research collected in the literature review and from Kovacs (2004), in conjunction with the administration of seven interviews, provided the answers to research questions identified in section one:

\section{Research Questions}

RQ1: What perceptions do teachers have about real world versus service learning projects?

RQ2: What perceptions do college students have about service learning projects?

RQ3: What perceptions do clients/community organizations have about service learning projects?

This exploratory study was designed utilizing qualitative research methods. Face-to-face, phone, and e-mail interviews were conducted to gather data. The target population for this study was comprised of Thiel College students and citizens from the surrounding town of Greenville, PA. Thiel College is a small, four-year institution located in western Pennsylvania. It is a Lutheran faith-based liberal arts school with a current enrollment of approximately 950 students. Greenville, located in Mercer County, is about 80 miles from both Pittsburgh and Cleveland, OH. The two SLP clients, both located in Greenville, were The Literacy Council of Mercer County and Holy Trinity Lutheran Church. Conducting this qualitative study involved conducting a face-to-face interview with current students. Phone interviews and e-mails were administered to past students and clients. Only one request was asked of participants: list the advantages and disadvantages of participating in SLPs. The responses to this question were collected and are depicted in table form in section four.

Section two of this paper discussed the methods used to conduct this qualitative study. The methodology helped the researcher better understand the perceptions of teachers, college students, and clients who have previously participated in a SLP. This study provides practical research applicable to the fields of Information Systems and Communication.

\section{RESULTS - ADVANTAGES \& DISADVANTAGES}

Peterson et al. (2006) felt that service-learning projects have an impact on faculty productivity. The time commitment is great due to answering student questions and communication with the community organization(s). Faculty not only have to manage the service learning project, but they also have to fulfill campus commitments, make sure the project meets the course objectives, and possibly maintain an ongoing relationship with and commitment to the various projects. Faculty must realize that service learning projects become a personal commitment, and enthusiasm toward the projects must remain high to successfully add this learning component to the pedagogy of a course and within the community.

Additionally, Peterson et al. (2006) found SLP limitations, including confinement to the semester schedule/academic year and proper placement of the project in the students' curriculum. Peterson et al. (2006) suggest that limitations can be overcome by careful planning. Peterson et al. (2006) also state that community partners need to be aware of university policies regarding procedures. For this project, the instructor created a contract for both the learning institution to sign and the community partner, which clarifies the roles of the involved parties. An additional challenge of including service learning into the curriculum involves the stability of the projects once the learning institution has completed the project. Changes are going to occur within the organization that demand systems be updated; and, at a learning institution the student and faculty populations are always changing. For example, if a faculty member led a continual service learning project and that faculty member left, oftentimes the service-learning project would end.

A thorough analysis of research in the area of service learning performed by Mareck et al. (2004), Mayne \& Glascoff (2002), Redman \& Clark (2002), Mueller \& Norton (2005), Mueller \& Norton (2005), “Service Learning in Writing Courses" (n.d.), showed the following benefits from the perspectives of the students, community organizations, and academic institutions. 
Volume XII, No. 2, pp. 22-29, 2011

- Students:

o strengthened interdisciplinary teamwork;

0 heightened social awareness and social justice;

o greater articulation of their own professional roles;

o improved problem-solving skills;

0 taught priority setting;

o understood differing cultural and rural perspectives;

o more socialized into their profession(s);

o gained personal insights into moral sensitivity;

o connected theory and practice;

o developed critical thinking skills.

- Community:

o created short- and long-term solutions to problems;

o improved access to campus resources;

o greater opportunities to contribute to the educational preparation of students ("Service Learning in Writing Courses,” n.d.).

- $\quad$ Academic Institution:

o provided a visible link with the community;

o formed collaborative relationships;

o involved faculty and students in local and state issues;

o increased preparation of graduates;

o enhanced appeal to potential financial donors and volunteers to the institution.

The following four tables illustrate the research collected in this study. Table 1 and Table 2 were adapted from Kovacs' (2004) study to display the teachers' perspectives on the advantages and disadvantages of simulation versus service learning projects (SLPs). Table 3 and Table 4 display the students' and clients' perspectives on the advantages and disadvantages of SLPs. This research was gathered via interviews as overviewed in section two.

Table 1 - Service Learning Projects (adapted from Kovacs, 2004)

\begin{tabular}{|c|c|}
\hline \multicolumn{2}{|c|}{ Service Learning Projects } \\
\hline Advantages & Disadvantages \\
\hline $\begin{array}{l}\text { - Working with an “actual” } \\
\text { client/community organization/business } \\
\text { Improves: } \\
\text { o communications skills } \\
\text { o interviewing } \\
\text { o problem solving } \\
\text { o conflict resolution } \\
\text { o oral and written communication } \\
\text { o learning how to “work” with others } \\
\text { - SLPs have “real” meaning, not artificially } \\
\text { invented } \\
\text { Promotes community/industry/university } \\
\text { relationships } \\
\text { Opens employment opportunities }\end{array}$ & $\begin{array}{ll}\text { - } & \text { Time consuming } \\
\text { - } & \text { Risky - a non controlled environment } \\
\text { - } & \text { Possible conflict with client or business } \\
\text { - } & \text { Group conflicts } \\
\text { - } & \text { Incomplete project can be a major issue: } \\
\text { resolve this by being clear to the client at } \\
\text { the beginning of the project that the project } \\
\text { may or may not end up getting completed }\end{array}$ \\
\hline
\end{tabular}


Volume XII, No. 2, pp. 22-29, 2011

\section{Results - Research Question 1}

Research Question One (RQ1): What perceptions do teachers have about real world versus service learning projects?

Table 1 displays the results of RQ1 by bulleting the advantages and disadvantages of SLPs from the teachers' perspectives.

Table 2 displays the results of RQ1 by bulleting the advantages and disadvantages of Simulated Course Projects from the teachers' perspectives.

Table 2 - Simulated Course Projects (adapted from Kovacs, 2004)

\begin{tabular}{|c|c|}
\hline \multicolumn{2}{|c|}{ Simulated Project } \\
\hline Advantages & Disadvantages \\
\hline $\begin{array}{ll}\text { - } & \text { Working with a knowledgeable end-user } \\
\text { (instructor) } \\
\text { - } & \text { Limited community involvement } \\
\text { - } & \text { Perceived “equity” among project groups } \\
\text { - } & \text { Incomplete projects not an issue }\end{array}$ & $\begin{array}{ll} & \text { Minimal decision making and problem } \\
\text { - } & \text { Lalving experiences } \\
\text { - } & \text { Lacks of risk taking practice } \\
\text { - } & \text { Perception that end-user (instructor) has all } \\
\text { of the answers }\end{array}$ \\
\hline
\end{tabular}

\section{Results - Research Question 2}

Research Question Two (RQ2): What perceptions do college students have about Service Learning Projects?

Table 3 displays the results of RQ2 by bulleting the advantages and disadvantages of SLPs from the students' perspectives.

Table 3 - Student Perspective on SLP's

\begin{tabular}{|c|c|}
\hline \multicolumn{2}{|c|}{ Student Perspective - Service Learning Projects } \\
\hline Advantages & Disadvantages \\
\hline $\begin{array}{l}\text { - } \quad \text { Get Experience in a real world setting } \\
\text { - } \\
\text { cxperience dealing with clients: student to } \\
\text { - } \quad \text { Experience with time management project } \\
\text { - } \quad \text { Experiences working team/groups } \\
\text { some staff and clients }\end{array}$ & $\begin{array}{l}\text { - } \quad \text { Clients do not understand what can and } \\
\text { cannot be done on a website } \\
\text { - } \quad \text { Clients do not comprehend web standards } \\
\text { - Students feel like clients do not want to } \\
\text { listen to student opinions on modern web } \\
\text { site designs and practices } \\
\text { - When showing clients the site they talk } \\
\text { about implementing new ideas and this } \\
\text { makes the students feel like all of their } \\
\text { hard work was not needed } \\
\text { - Clients can be indecisive with decisions: } \\
\text { web site layout and design, time is wasted } \\
\text { while waiting for their decisions to } \\
\text { continue on with site development } \\
\text { Client does not understand how time } \\
\text { management works when working with } \\
\text { creating websites } \\
\text { Clients do not understand formal web } \\
\text { language vocabulary: students have a hard } \\
\text { time being able to describe things to clients } \\
\text { because of limited technical knowledge }\end{array}$ \\
\hline
\end{tabular}


Volume XII, No. 2, pp. 22-29, 2011

Results - Research Question 3

Research Question Three (RQ3): What perceptions do clients/community organizations have about Service Learning Projects?

Table 4 displays the results of RQ3 by bulleting the advantages and disadvantages of SLPs from the clients' perspectives.

Table 4 - Client Perspective on SLP's

\begin{tabular}{|c|c|}
\hline \multicolumn{2}{|c|}{ Client Perspective - Service Learning Projects } \\
\hline Advantages & Disadvantages \\
\hline $\begin{array}{ll}\text { - } & \text { Price/Cost } \\
\text { - } & \text { Able to help students } \\
\text { - } & \text { Time saver for community or non-profit } \\
\text { organizations } \\
\text { - } & \text { Effective Way to Working with Local } \\
\text { - } & \text { Pollege } \\
\text { - } & \text { Provided time management } \\
\text { - } & \text { Experience } \\
\text { - } & \text { Getting close to working Thiel College } \\
& \text { students }\end{array}$ & $\begin{array}{l}\text { - } \quad \text { Time Constraints } \\
\text { - } \quad \text { Not being able to meet face to face more }\end{array}$ \\
\hline
\end{tabular}

This exploratory study examined the perceptions of teachers, students, and clients who participated in a servicelearning project (SLP) for an advanced web development course. After analyzing the four tables of results, this research indicates that SLPs prove to be more of an advantage to all parties involved. The teachers suggested that SLPs offer 12 advantages and five disadvantages. The students' perceptions provided seven disadvantages and five advantages. The clients' or community organizations' perceptions were high and provided eight advantages and two disadvantages.

\section{COURSE ORGANIZATION}

\section{Steps to getting started with service learning projects}

Preiser-Houy et al. (2006) and Strand et al. (2003) together found that service learning projects validate multiple sources of knowledge, from the experiential knowledge and viewpoints of community members, to the specialized knowledge and skills of students and university faculty. As observed from experience and gathered research, it is clear that a single blueprint does not exist; however, the author of this paper has created a method that has worked well at her institution. A key piece of the blueprint is derived from Kuh (2005) who asserts that institutions that "live" or meet their mission statements are the schools that are impressive in fostering student engagement. Service learning projects powerfully express the way an institution can "live" its mission. Additionally, Peterson et al. (2006) believe service-learning projects meet community needs. Beginning a service-learning project can be a challenge; however, if you complete the following three steps, implementation of this new pedagogy will likely be a success. The first step is to find a good match between academia and the community organization (Rodgers et al., 2004). The second step requires the formation of a strong relationship (Rodgers et al., 2004). The third step involves making sure the role or expectation has been clarified. In this paper, both the Literacy Council of Mercer County and Holy Trinity initiated the contact with Thiel College in regard to the redevelopment of their web sites. The course instructor/researcher contacted the community organizations and then met with the individuals seeking completion of this project. Through observation and reflection, the researcher considered each project successful because of the collaborative efforts on all sides of the relationships. Moreover, the researcher felt that step 2 was the most difficult and recommended that this step be placed in a position of high importance for those embarking on a service-learning project. Reflection on past projects suggested that this could present a challenge because all 
Volume XII, No. 2, pp. 22-29, 2011

participants must fully respect the formation of the relationships between the institution and the community organization(s).

Researchers have investigated project-based learning in a wide variety of disciplines and settings and have generally found it to be effective in increasing student motivation. Moreover, service learning has been shown to improve student problem solving and higher order thinking skills by addressing different learning styles and providing students with an integrated learning situation (Hutchings and Wutzdorff, 1998; Albanese and Mitchell, 1992; Buck Institute, 1999; Tretten, and Zachariou, 1995). Project-based learning, unlike the traditional textbook/lecture approach, motivates students to do additional work, illustrates to students the value of the material covered, and most importantly, provides practical experiences that enrich students' academic experiences.

The following model in Figure 1 illustrates the course steps the researcher used in two completed service-learning projects.

\section{Figure 1: Project Based Model}

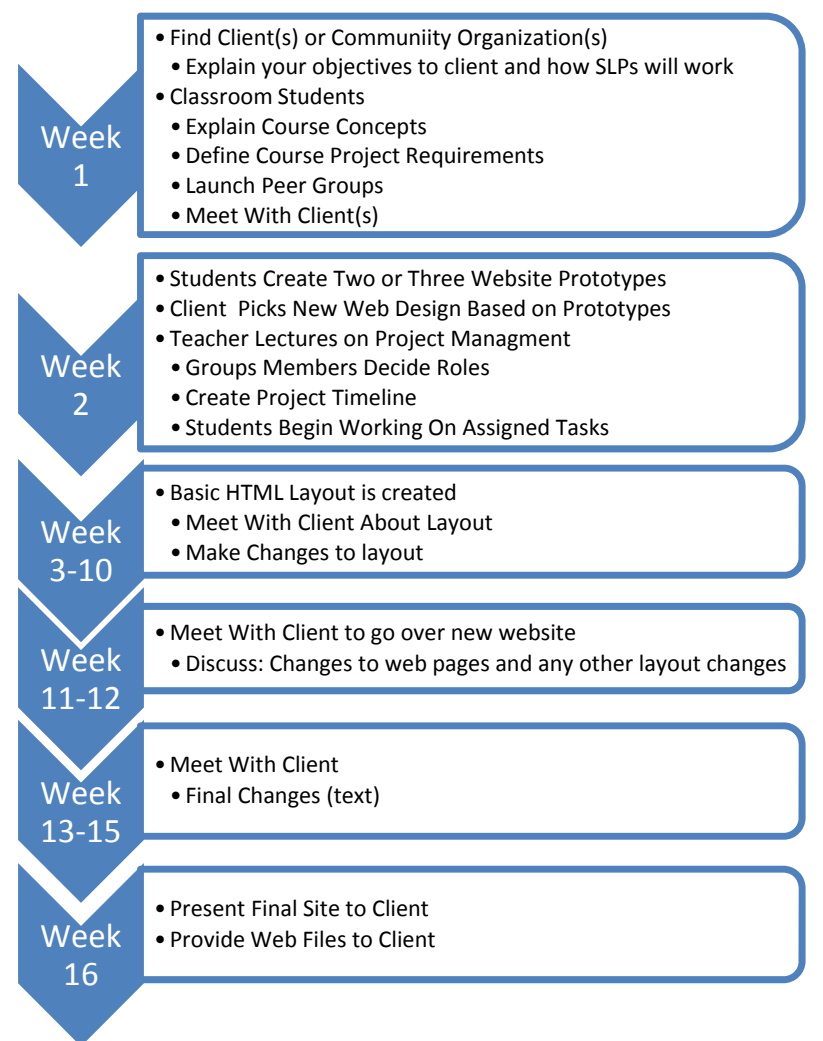

\section{CONCLUSION}

The findings of this project, as well as many of the studies referenced in this paper, show that in order for students to grasp the learning outcomes set forth by a learning institution, courses should include personal development, interpersonal development, and academic learning. Preiser-Houy et al. (2006) stated the following:

1. Personal development outcome is comprised of self-knowledge and personal efficacy;

2. Interpersonal development outcome consists of communication, collaboration, and leadership skills; and

3. Students' academic learning encompasses domain specific and general knowledge and skills. 
Matthew, George, Kimberly, Nukhet, Essam (2007) conducted an exploratory study on the value of service learning projects and their impact on community service involvement and critical thinking. The purpose of their study was to attempt to capture some of the principal benefits and factors attributable to service learning or community service projects from a student perspective. The Matthew et al. (2007) study consisted of a sample of 67 males and 83 females (16 graduate, 71 seniors, and 63 juniors). The findings of Matthew et al. (2007) indicated that students believe their college experience is preparing them for the job market, critical thinking has been enhanced, and their college academic experiences have emphasized community service upon graduation. Matthew et al. (2007) further noted that the study had practical implications and the results of the study can increase one's knowledge of the benefits of service learning, since so much emphasis is currently being placed on improving the critical thinking and problem-solving abilities of undergraduate business students. Moreover, Matthew et al. (2007) stated that the originality and value of this study could benefit practitioners who are interested in understanding the impact that service learning can have on the problem-solving abilities of potential employees. Research by Matthew et al. (2007) supports the data collected for this paper in finding that service learning projects improve the critical thinking and problem-solving abilities of undergraduate web programming students. The researcher also agrees with Matthew et al. (2007) that additional research needs to be conducted to determine if students with service learning experiences are generally superior in terms of their problem-solving skills to students who lack similar experiences. Thus, evidence of a service-learning component on a student résumé could add value to the potential employer.

Service learning projects implemented into the curriculum are time consuming, but are valuable in the development of critical thinking and performance skills for students, as well as being a positive way to introduce social awareness and opportunities for professional behaviors. Any community organization wanting to improve its business on a technology level should consider approaching a local learning institution to encourage collaborative service learning projects within their organization or target community population, according to Peterson et al. (2006). Furthermore, involvement in such activities positively influences faculty and student involvement and increases the success of any academic discipline. The research conducted in this study project supports these findings.

The researcher affiliated with this project agrees with other scholars that the real work of computer or information technology (IT) professionals is complex and multidimensional. In fact, business clients and IT managers expect their IT personnel to understand their technical roles and the roles collaborators, facilitators, and leaders. Service learning takes education to a higher level of learning by including learned technical, personal, and interpersonal skills. The IT environment is continually changing, and the skills learned via service learning projects enable students to become effective, credible, and trustworthy in their future careers.

Do you want to start a successful service-learning project? Consider the following:

1. early planning;

2. time consuming;

3. ongoing communication;

4. opportunities for students to reflect and present on the learning involved in the project.

Success is considered a top priority in the United States. In America, success often includes fortune, fame, power, and pleasure. However, as humans, we tend to still have other needs to be fulfilled. One of those needs is satisfaction or for people to feel like they have fulfillment in life. Satisfaction and fulfillment are obtained when an individual feels like he or she has made a contribution to something or helped complete something. Therefore, it is this researcher's opinion that success and satisfaction are interdependent because an individual cannot have true success unless all needs are met. Fulfillment can also be considered as the investment in others and service learning is one way to fulfill the satisfaction need. Service learning provides the student with the three A's: authority, attitude, and anxiety. When a student completes a service-learning project, the student learns how to submit to authority, create a healthy attitude, and deal with anxieties or stresses of his or her chosen career. The three A's are essential when students begin their careers after graduating. Service learning also provides the guided experience that is priceless in today's world. 
Volume XII, No. 2, pp. 22-29, 2011

\section{REFERENCES}

1. Albanese, M. \& Mitchell, S. (1993). Problem-based learning: A review of literature on its outcomes and implementation issues. Academic Medicine, 68(1), 52-81.

2. Buck Institute (1999). Project based learning. [Online]. http://www.bie.org/pbl [8 May 2000].

3. Eyler, Janet and Dwight E. Giles (1999), Where's the Learning in Service-Learning? San Francisco, California: Jossey-Bass.

4. Eyler, J. (2002). Reflecting on service: Helping nursing students get the most from service learning. Journal of Nursing Education, 41(10), 453-456.

5. Furco, Anthony (2002), "Is Service-Learning Really Better Than Community Service?" In Furco, A. and Billing, S. (Eds.), Service-Learning: The Essence of the Pedagogy, Greenwich, Connecticut: Information Age Publishing. pp.23 -50.

6. Hutchings, P. and A. Wutzdorff, 1988, "Experimental learning across the curriculum: Assumptions and principals.” New Directions for teaching and Learning, 35, 5-19.

7. Jacoby, Benjamin (1996), "Service-Learning in Today's Higher Education". In Jacoby, B. and Associates (Eds.), Service-Learning in Higher Education. pp. 3 - 25.

8. Kovacs, P. (2004). A project-based model for an advanced web site design and e-commerce course. Proc ISECON, 21, 1-9.

9. Kuh, G. D. (2005). Student success in college: creating conditions that matter. San Francisco: Jossey-Bass.

10. Mareck, D. G., Uden, D. L., Larson, T. A., Shephard, M. F., \& Reinert, R. J. (2004). Rural interprofessional service learning: The Minnesota experience. Academic Medicine, 79(7), 672-676.

11. Matthew, J., George W., S., Kimberly, G., Nukhet, H., \& Essam, I. (2007). An exploratory study on the value of service learning projects and their impact on community service involvement and critical thinking. Quality Assurance in Education: An International Perspective, 15(3), 318-333. Retrieved from EBSCOhost.

12. Mayne, L., \& Glascoff, M. (2002). Service learning: Preparing a healthcare workforce for the next century. Nurse Educator, 27(4), 191-194.

13. Mueller, C., \& Norton, B. (2005). Service learning: Developing values and social responsibility. In D. M. Billings \& J. A. Halstead (Eds.), Teaching in nursing (pp. 213-227). St. Louis, MO: Elsevier Saunders.

14. Peterson, B., Yockey, J., Larsen, P., Twidwell, D., \& Jorgensen, K. (2006). Service-Learning Projects: Meeting Community Needs. Home Health Care Management \& Practice, 18(4), 315-322.

15. Preiser-Houy, L., \& Navarrete, C. (2006). Exploring the Learning in Service-Learning: A Case of a Community-Based Research Project in Web-Based Systems Development. Journal of Information Systems Education, 17(3), 273-284.

16. Redman, R \& Clark, L. (2002). Service-learning as a model for integrating social justice in the nursing curriculum. Journal of Nursing Education, 41, 446-449.

17. Rodgers, M. W. (2001). Service learning: Resource allocation. Nurse Educator, 26(5), 244-247.

18. Tretten, R. \& P., Zachariou, 1995, "Learning about project based learning.” Paper prepared for the Autodesk Foundation, San Rafael, CA. 